\title{
THE RELATIONSHIP BETWEEN LUNAR PHASES AND THE EMERGENCE OF THE ADULT BROOD OF INSECTS
}

\author{
NOWINSZKY, L. ${ }^{1}{ }^{*}-$ PETRÁNYI, G. ${ }^{2}-$ PUSKÁs, J. ${ }^{1}$ \\ ${ }^{1}$ University of West-Hungary, Savaria Campus, H-9701 Szombathely, Károlyi G. Square 4. \\ ${ }^{2}$ Corvinus University of Budapest, Department of Mathematics and Informatics \\ H-1118 Budapest, Villányi út 29-43. \\ *Corresponding author \\ e-mail: Inowinszky@gmail.com \\ (Received $22^{\text {nd }}$ February 2010 ; accepted $29^{\text {th }}$ March 2010)
}

\begin{abstract}
Based on many years of light trap catch data by the Hungarian Light Trap Network and other traps, we have examined the relationship between the emergence of the adult broods of insects and lunar phases. The summarized results of adult brood emergences were plotted against 30 phase angle divisions, our special dividing method of the lunation also used in our previous works. We have found that the emergence of the adult brood of several Macrolepidoptera and Coleoptera species is associated with a special lunar phase, most often with the Last Quarter.
\end{abstract}

Keywords: insects, moon phases, first specimen of generation

\section{Introduction}

A reliable prediction of the adult brood emergence of pest insect species is of extreme importance in plant protection. Environmentally sound, effective and economical protection treatments are usually timed to correspond with a special phenological period of the pest species, which can generally be calculated with acceptable precision from the starting date of the adult brood.

By "adult brood" or "flight" we mean the length of the flight-period of a given adult generation of a species. The length of flight is usually longer than the lifespan of a single adult specimen. Adults are usually short-lived, thus flight can be considered as a time series of the difference of emerging and dying individuals. Accordingly, the aspect of flight reflects - at least partially - the hatching of imagos from the pupae, with some probably negligible delay. This aspect may also be modified by the number of individuals arriving to and departing from the given location.

The phenological phenomena of insects are connected to meteorological factors, including primarily temperature. The rate of the metabolic processes of poikilotherm insects is determined by the temperature of the environment. As a result of observations and experiments, scientists found that the beginning of the flight of numerous species correlate with the sum of heat units required for development. (Nowinszky 2004; Nowinszky et al., 2007, 2008)

\section{Review of literature}

In the view of several authors, the life cycle and thus the emergence of the adult brood of insects is possibly also in relation with lunar phases. Research in this field has mainly concentrated on short-lived species like Ephemeroptera, where the beginning and the culmination of the flight occur in quick succession. Hora (1927) compared old 
records on some Ephemeroptera - the first one from 1744! - with the lunar phases and found that the adults emerged most frequently in the vicinity of a Full Moon. Pongrácz (1933) experienced several times that the adults of the mayfly species Polymitarcis virgo Oliv. emerged en masse right after a Full Moon. According to Csongor and Móczár (1954), the swarming of Palingenia longicaudata Oliv. (Ephemeroptera) is affected by rising air pressure as well as rising air and water temperatures and the lunar phases. After an examination of the records of the greater swarms of mayflies, Móczár (1957) pointed out that they had all occurred one day after a Full Moon or a New Moon. Between March 1953 and April 1955, Hartland-Rowe (1955) observed that the 22 swarms of Povilla adusta Naval (Ephemeroptera) at Lake Victoria and Lake Albert happened in a 5-day vicinity of - most often 2 days after - a Full Moon. Adults only live for about one hour. Between $10^{\text {th }}$ and $21^{\text {st }}$ August 1954, 1521 specimens were collected by light trap, 44\% arriving on the second day after a Full Moon. The author proposes this lunar rhythm only to be true near the Equator where day length and temperature are quite stable throughout the year. Also at Lake Victoria, MacDonald (1956) found that the swarming of some unidentified Chironomus and Chaoborus species occurred shortly after a New Moon. The author takes the influence of the Moon on the biology of these species as evidence. For a further examination of this question, Corbet (1958) by use of Robinson-type light traps equipped with $125 \mathrm{~W}$ mercury vapour bulbs, collected Plecoptera, Ephemeroptera, Chaoborus and Trichoptera species on one hundred consecutive nights on the shore of Lake Victoria. In four of the 37 species examined, the number of individuals showed a periodical change corresponding to the change of lunar phases. This phenomenon could not be proved for the rest of the species. In his view, the timing of the highest and lowest catch in the vicinity a Full or a New Moon does not confirm the assumption that the light of the Moon has an influence on the light trap catch. The reason might rather be the lunar rhythm of adult emergence. Relying upon their suction trap catch results, Perfect and Cook (1982) presume a synchronization mechanism between lunar phases and the flight activity of the species living in the tropics where the change of temperature is moderate. According to Fryer (1959), the rhythm of the development of the non-biting midge species Chironomus brevibucca Kief. follows Moon Phases closely. Adults emerge in great numbers after a Full Moon. On the other hand, Ito et al. (1993) did not observe a synchronicity between lunar phases and the emergence of Scotinophara coarctata (Thunberg) (Heteroptera: Pentatomidae).

It is important to clearly separate lunar influence on adult brood emergence and one on activity. Fryer (1959) also notes that in the case of Chironomus brevibucca Kief, the two periods inevitably coincide. Although it is not sure that lunar influence also affects the beginning of the flight of longer-lived insects. Numerous authors share the view that lunar phases might synchronize the biological rhythm of Lepidoptera. Persson (1974) observed an unfavourable influence of moonlight on the oviposition of Heliothis zea Boddie. According to a presumption by Nemec (1971), the generation cycles of Heliothis zea Boddie are synchronized with Moon Phases. The results of Agee et al. (1972) also suggest the activity and life cycle of Heliothis zea Boddie to be synchronized with lunar phases. Possibly, several other physical phenomena - like the maturity of the foodplant, temperature or other factors - might also be responsible for this lunar rhythm.

Field observations indicated that the peak of the emergence and mating of tobacco budworm (Heliothis virescens Fabr.) occurred 8-9 days before the capture-peaks in

APPLIED ECOLOGY AND ENVIRONMENTAL RESEARCH 8(1): 51-62. http://www.ecology.uni-corvinus.hu • ISSN 15891623 (Print) • ISSN 17850037 (Online) (C) 2010, ALÖKI Kft., Budapest, Hungary 
pheromone traps. In addition, mating peaks occurred 4 days before a Full Moon while trap capture peaks 4 days after a Full Moon (Raulston et al., 1979).

Bowden and Gibbs (1973) find it worth considering whether lunar phases synchronize flight activity in some stage of development. According to Bowden (1973a), lunation determines an important biological rhythm for the different insect species. The conclusion of Danthanarayana (1986), that Moon periodicity is unrelated to the time of the appearance of the Moon above the horizon is of great importance. This precludes the possibility that the observed flight behaviour would be a direct visual response to the Moon or to moonlight. In his view, the periodicity of the Moon may have the advantage of making survival possible via migration and contributing to the synchronization of emergence and flight in favour of mating and reproduction.

Roux and Baumgartner (1995) operated pheromone traps on Tunisian potato fields between 1986 and 1991 to record the number of male specimens of Phthorimaea operculella (Zeller) weekly. A four-week cycle - presumably influenced by the Moon was identified.

Conlee (1995) analyzed 10 years of daily sex pheromone-baited trap capture data for the codling moth (Cydia pomonella L.) for lunar periodicity, using both statistical and non statistical methods in South-California. Using time series (spectral) analysis, a sine wave periodicity of approximately 30 days was detected in 6 of 10 annual spectra and at a significance level of $\mathrm{P}<0.05$ in a combined 10-year spectrum. Auto regression analysis failed to detect precise periodicity and showed that these trap captures are independent after 3 days. Frequency distributions of generation emergences over 10 years showed that $80 \%$ occurred within either 3 days of a New or a Full Moon. First true generation emergence was found to change according to coincidence of the lunar periodicity to annual constraints, and second generation emergence occurred 43.4 days (1.5 lunar cycles) later. A hypothetical model for this was developed and its potential accuracy compared with that of published degree-day models. This model has accurately predicted first and second generation codling moth emergences in southern California during the past two years.

\section{Materials and methods}

For our research, we used the complete Macrolepidoptera material of the forestry light trap operated in the Kámon Botanical Garden in Szombathely between 1962 and 1970, including data of 3395 adult broods. We have considered the catch of the first specimen of a species as the beginning of the flight. In the case of polyvoltine species, we only considered the first generation, if the generations were not clearly separable.

We have also processed data provided by the 49 observation posts of the National Agricultural and Forestry Light Trap Network on 31 species represented by more than 20 specimens from each generation (Nowinszky and Ekk, 1988). Most of our catch data come from the period 1959-1970, but we also utilized earlier data from the light trap network being developed steadily over the years as from 1953. We have processed the catch results of several important pest species until 1976. We have also worked with data on the winter moth Operophtera brumata L. for the period 1961-1976, including 203 adult broods. We were also provided with the catch data of the National Light Trap Network on the 245 and 151 adult broods of fall webworm Hyphantria cunea Drury for the periods 1953-1963 and 2000-2006, as well as on the 673 broods of the Common Cockchafer Melolontha melolontha L. for the period 1966-2006. 
We also used all data of the Macrolepidoptera caught by the special light trap operated by Varga and Mészáros (1973) in Becse (Voivodina, Serbia) between 1970 and 1973, and the Coleoptera data of the same trap collected from 1971.

We have downloaded the phase angle values of the Moon from the following URL: http://aa.usno.navy.mil/data.docs/MoonPhase.html. We have divided the $360^{\circ}$ phase angle of the full lunar month (lunation) into 30 divisions. The division in the $\pm 6^{\circ}$ phase angle value vicinity of a Full Moon $\left(0^{\circ}\right.$, or $\left.360^{\circ}\right)$ was named: 0 . Starting from here, divisions in the direction of the First Quarter until the New Moon were named: -1, -2, $3,-4,-5,-6,-7,-8,-9,-10,-11,-12,-13,-14$. Also starting from the Full Moon, divisions in the direction of the Last Quarter until a New Moon were named: 1, 2, 3, 4, $5,6,7,8,9,10,11,12,13$, and 14. The division including the New Moon was named: \pm 15 . All divisions include 12 phase angle values. We have arranged all nights of the observation period into one of these phase angle divisions (Nowinszky, 2003).

Consequently, we have assigned the day of the catch of the first specimen of all adult broods of all species to a phase angle division of the Moon, summarized the results, and finally we plotted in percentage the frequency of adult brood emergences falling into the different divisions.

\section{Results}

The beginning of the flight of the Macrolepidoptera species caught by the light trap working in Kámon Botanical Garden plotted against lunar phases is presented in Fig. 1.

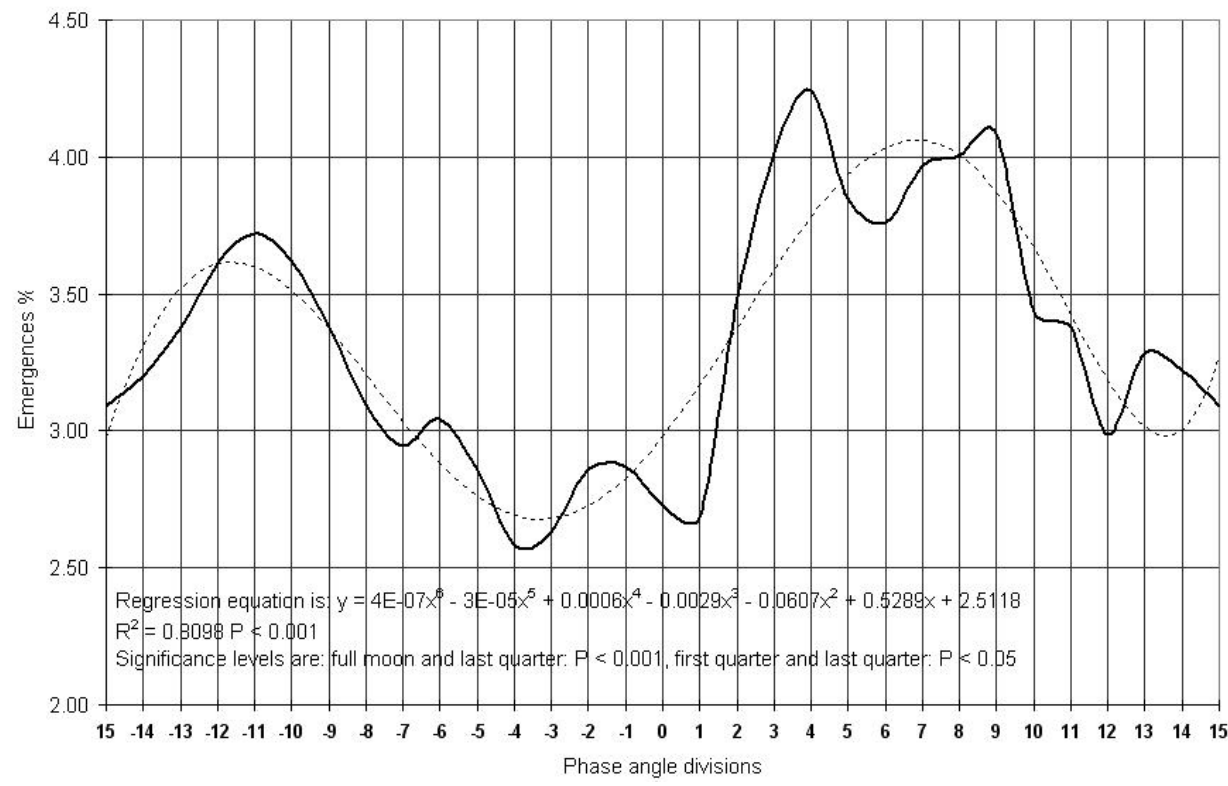

Figure 1. The emergence of the adult broods of the processed 31 Macrolepidoptera species caught by the light-trap working in Kámon Botanical Garden (1962-1970, 556 species)

The emergence of the adult broods of the processed 31 Macrolepidoptera species caught by the National Light Trap Network is illustrated in Fig. 2-6. Fig. 2 shows the summarized curve of the five species beginning to fly vicinity a Full Moon. Fig. 3 
includes the summarized curve of the species starting to fly in the vicinity the Last Quarter. The curves of 2 species starting to fly at a New Moon and after a Full Moon are illustrated in Fig. 4. Fig. 5 shows the curve of species starting to fly in the period of a New Moon and in the Last Quarter.

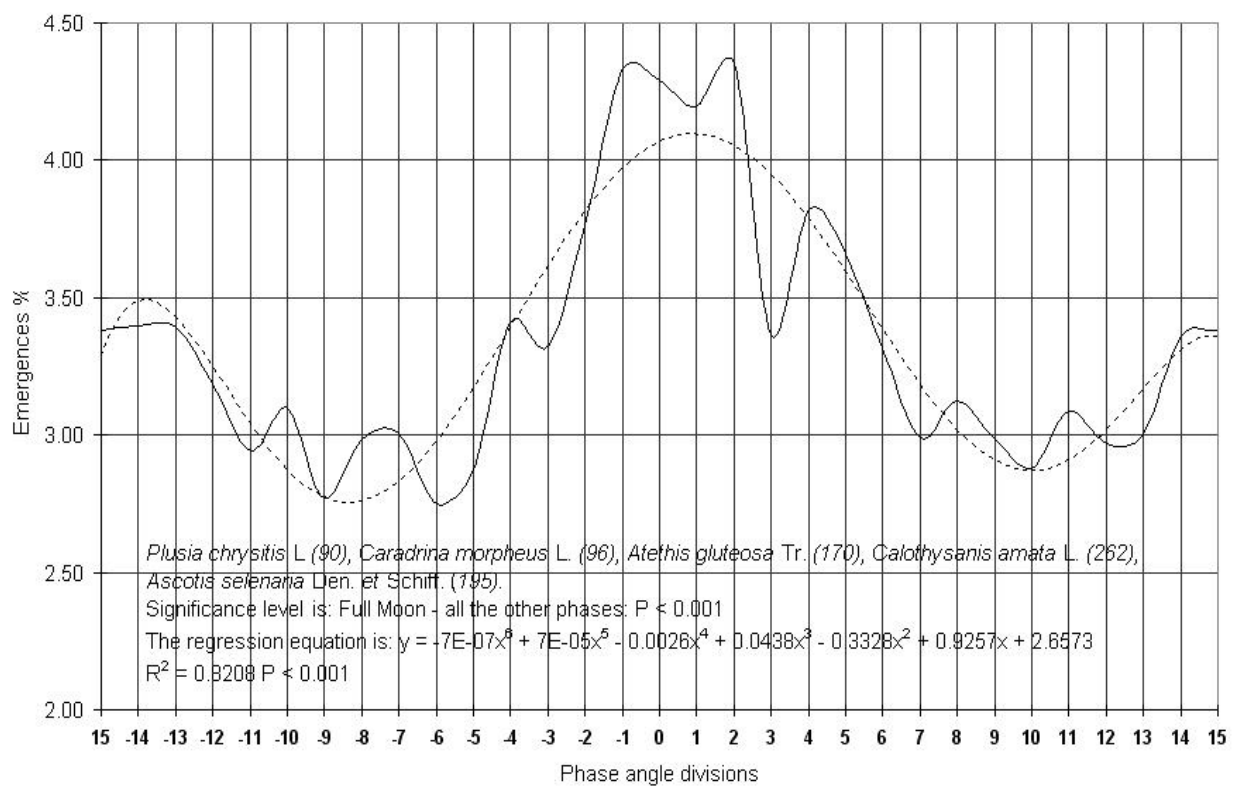

Figure 2. The emergence of the adult broods of the processed 5 Macrolepidoptera species caught by the National Light Trap Network. The summarized curve of the species beginning to fly in the vicinity of a Full Moon.

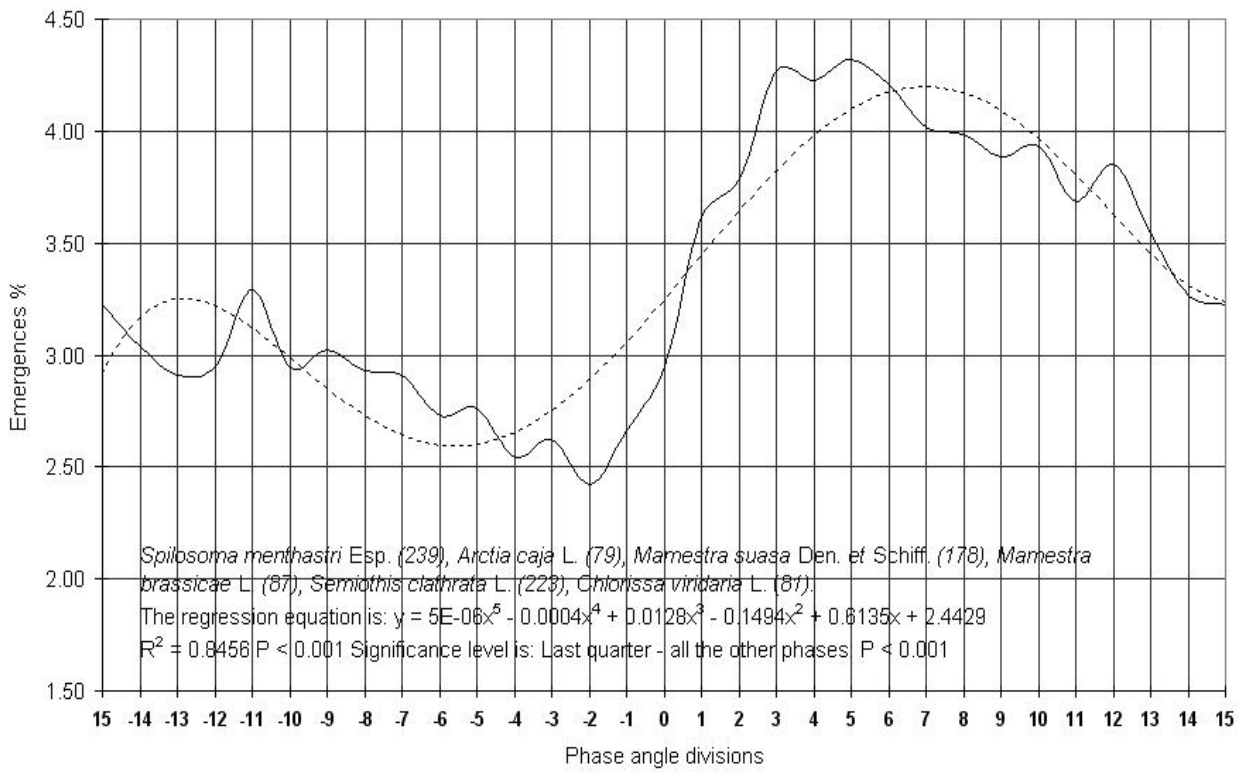

Figure 3. The emergence of the adult broods of the processed 6 Macrolepidoptera species caught by the National Light Trap Network. The summarized curve of the species beginning to fly in the vicinity of a Last Quarter 


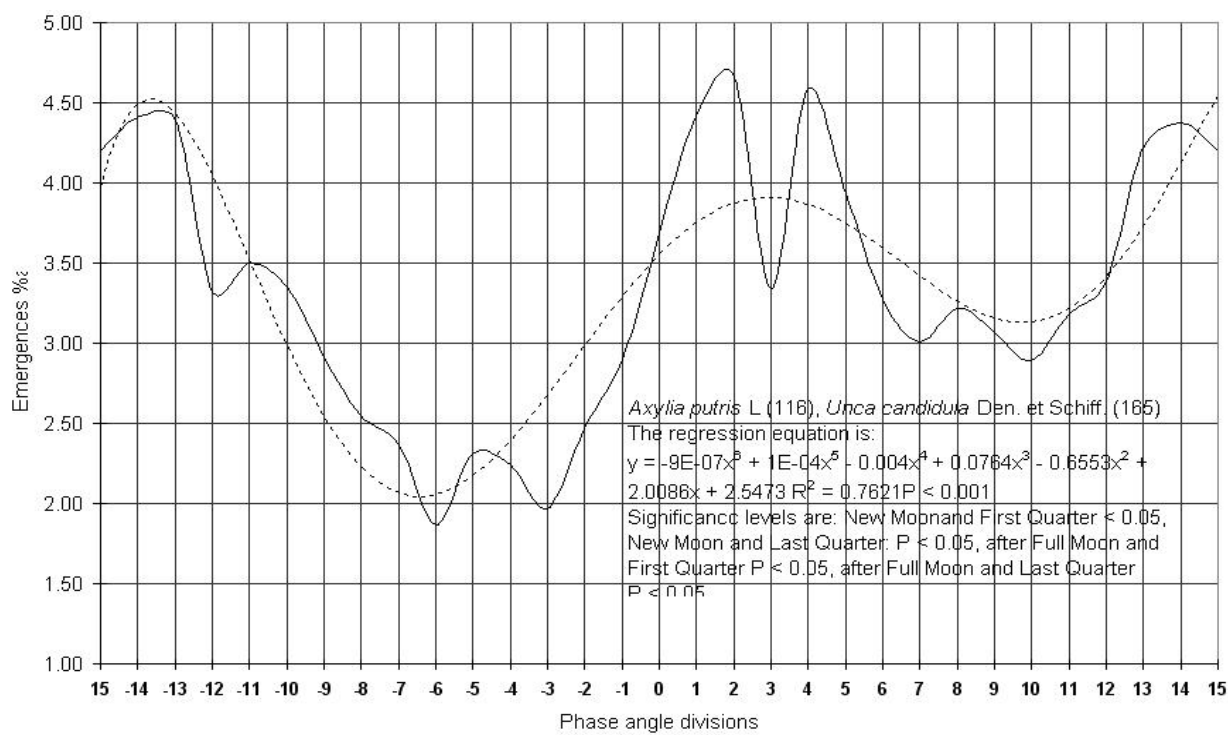

Figure 4. The emergence of the adult broods of the processed 2 Macrolepidoptera species caught by the National Light Trap Network. The summarized curve of the species beginning to fly in the vicinity of New Moon and after Full Moon

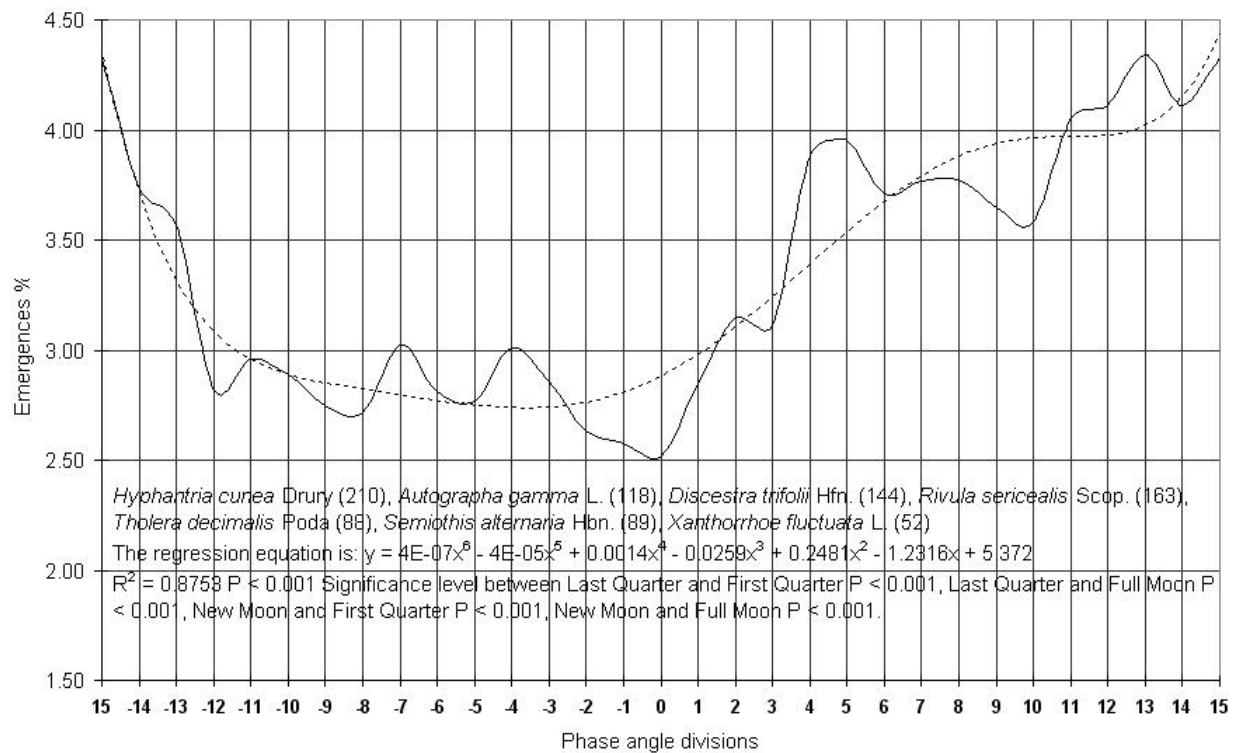

Figure 5. The emergence of the adult broods of the processed 7 Macrolepidoptera species caught by the National Light Trap Network. The summarized curve of the species beginning to fly in the vicinity of New Moon and Last Quarter 


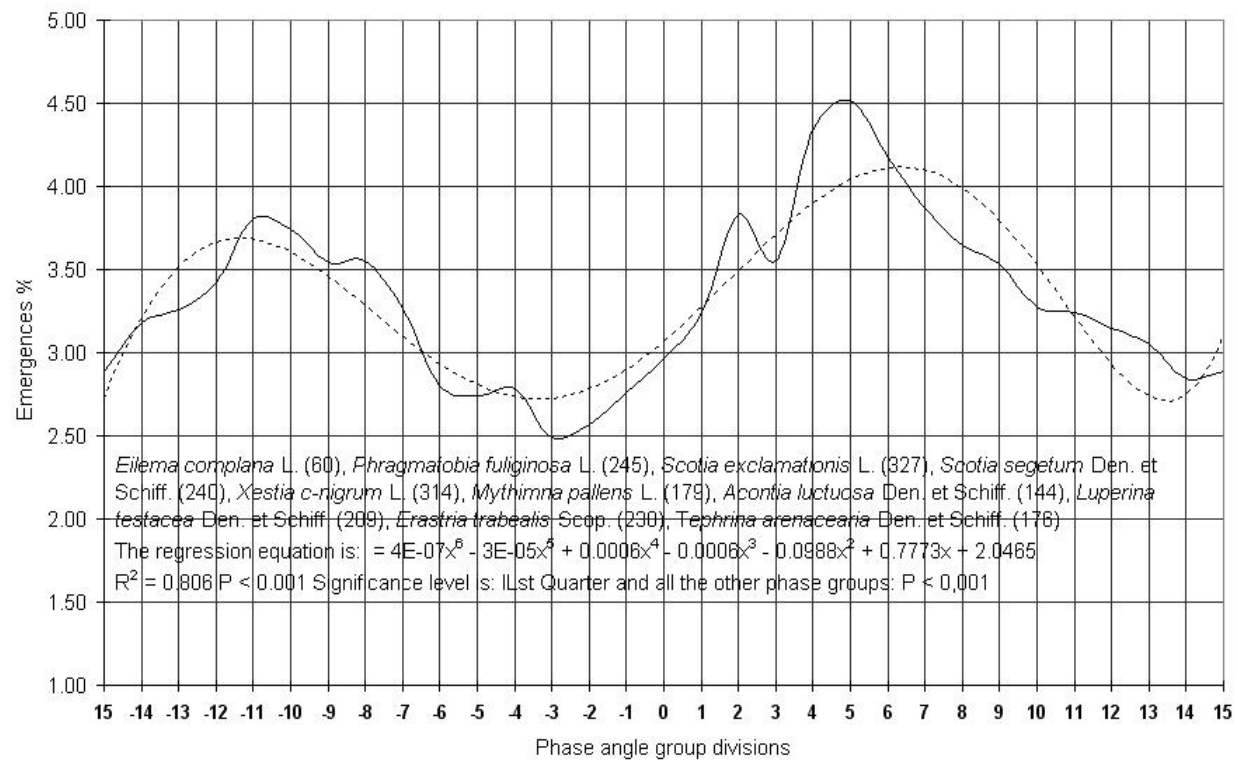

Figure 6. The emergence of the adult broods of the processed 10 Macrolepidoptera species caught by the National Light Trap Network. The summarized curve of the species beginning to fly in the vicinity of First quarter and Last Quarter

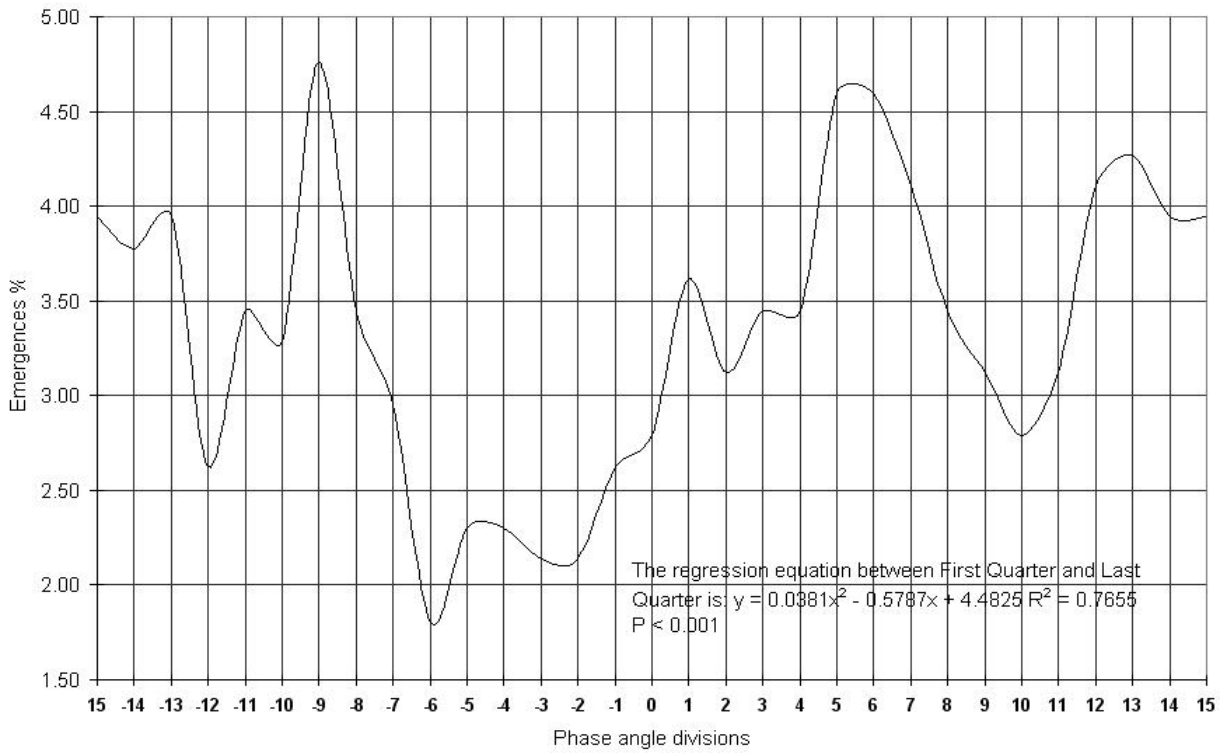

Figure 7. The emergence of the adult broods of winter moth (Operophtera brumata L.), depending on the lunar phases from the material of the National Light Trap Network (1961-1976)

In Fig. 6 species beginning to fly in the First and Last Quarters can be seen. It was in the case of a single species (Spilosoma lubricipeda Esp.) alone where no connection between the lunar phases and the beginning of flights could be proved. Fig. 7 shows the emergence of the adult broods of the Winter Moth Operophtera brumata L. plotted 
against lunar phases. The emergence of the adult broods of the Fall Webworm (Hyphantria cunea Drury) between 1953-1963 and 2000-2006 is illustrated in Fig. 8. Fig. 9 shows the beginning of 673 adult broods of the Common Cockchafer (Melolontha melolontha L.).

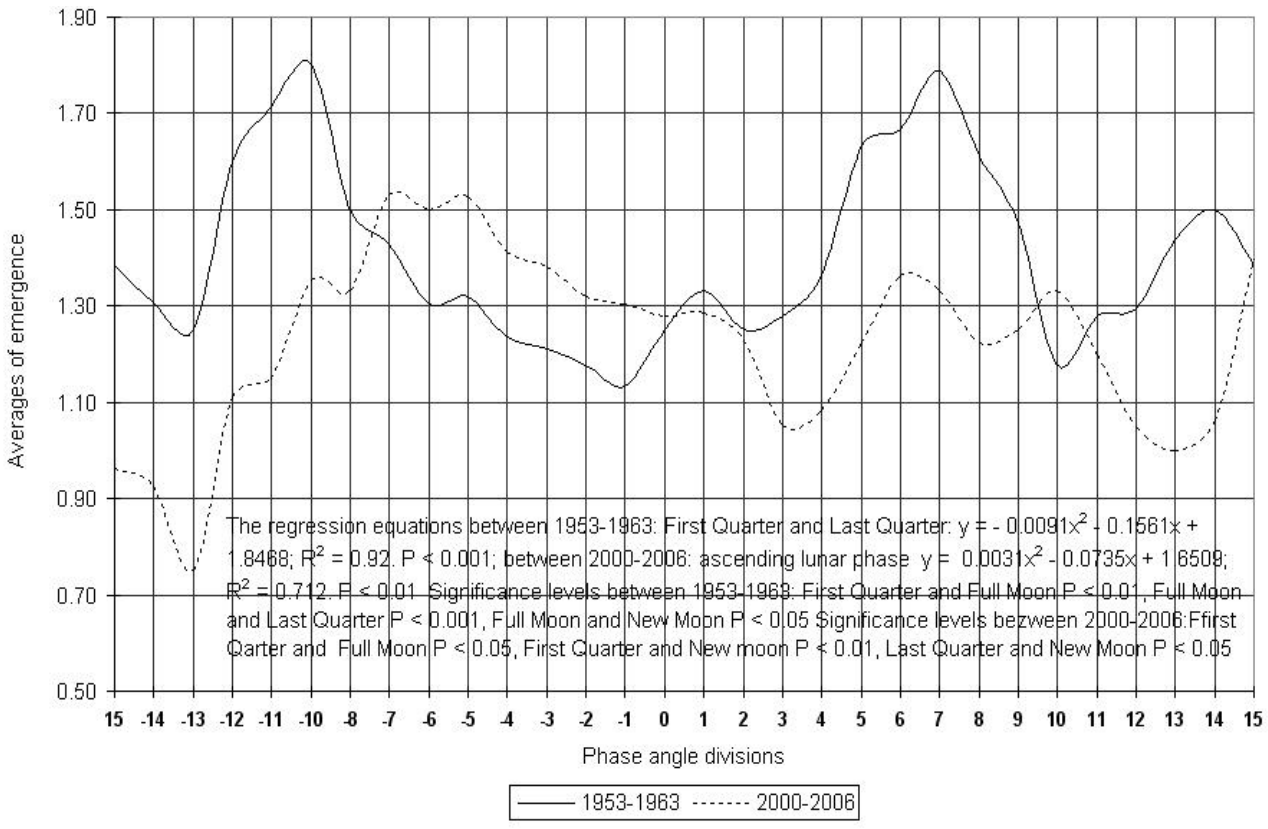

Figure 8. The emergence of the adult broods of fall webworm moth (Hyphantria cunea Drury), depending on the lunar phases from the material of the National Light Trap Network (1953-1963 and 2000-2006)

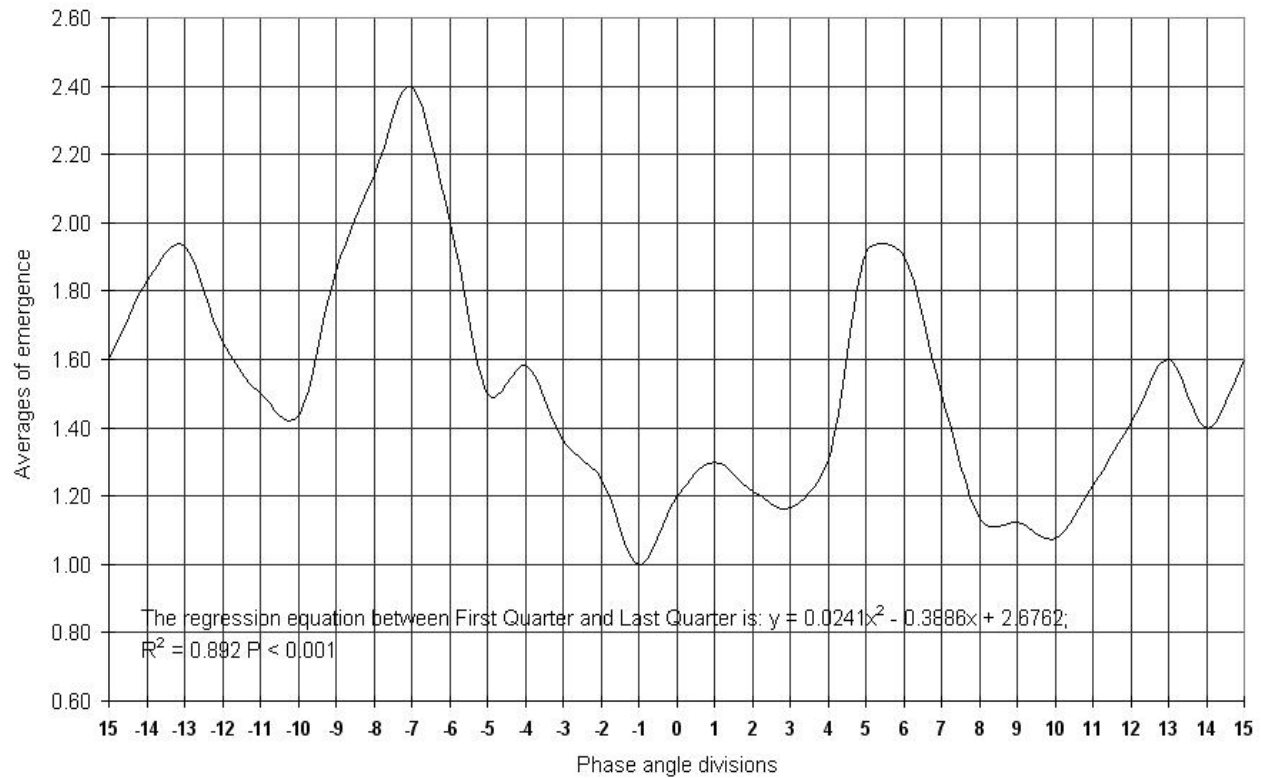

Figure 9. The emergence of the adult broods of common cockchafer (Melolontha melolontha L.), depending on the lunar phases from the material of the National Light Trap Network (1966-2006)

APPLIED ECOLOGY AND ENVIRONMENTAL RESEARCH 8(1): 51-62. http://www.ecology.uni-corvinus.hu • ISSN 15891623 (Print) • ISSN 17850037 (Online) (c) 2010, ALÖKI Kft., Budapest, Hungary 
The emergence of the adult broods of the processed 73 Macrolepidoptera and 93 Coleoptera species caught by the light trap of Varga and Mészáros are illustrated in Fig. 10 and Fig. 11.

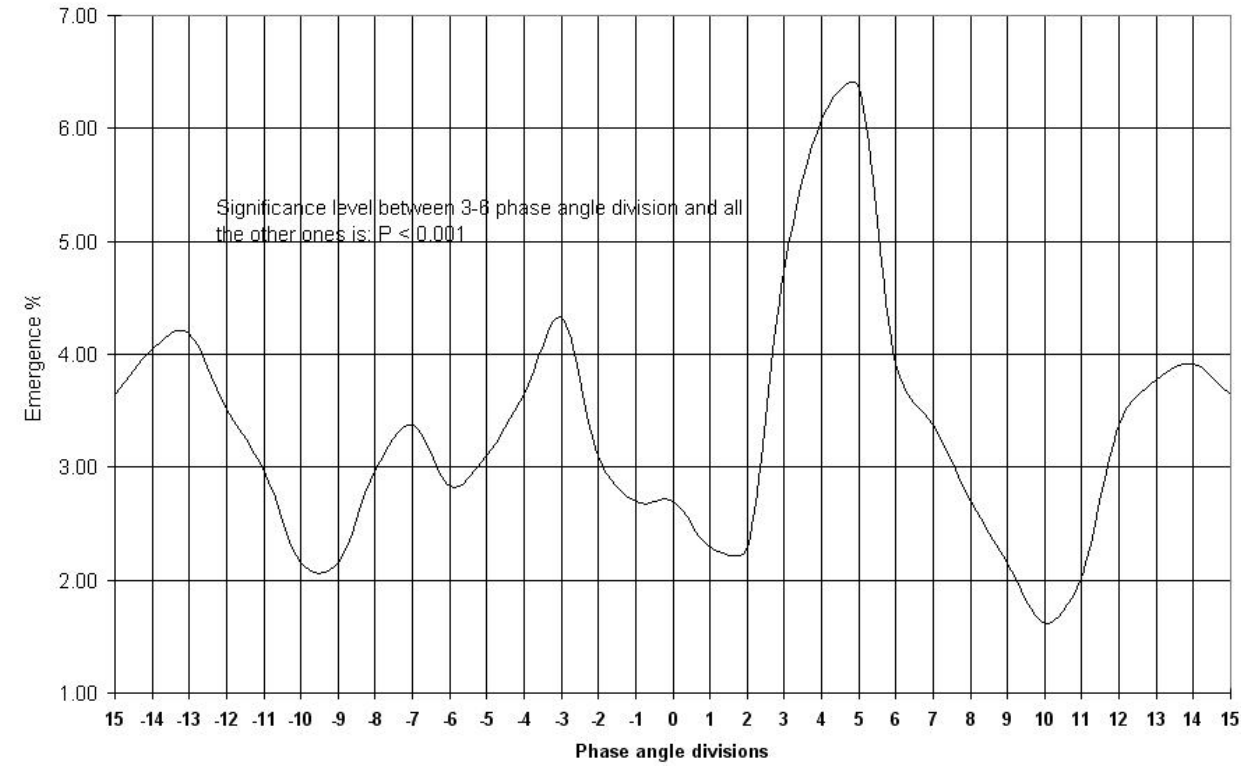

Figure 10. Emergence of Macrolepidoptera species caught by the Varga-Mészáros type lighttrap in Becse (Voivodina, Serbia)

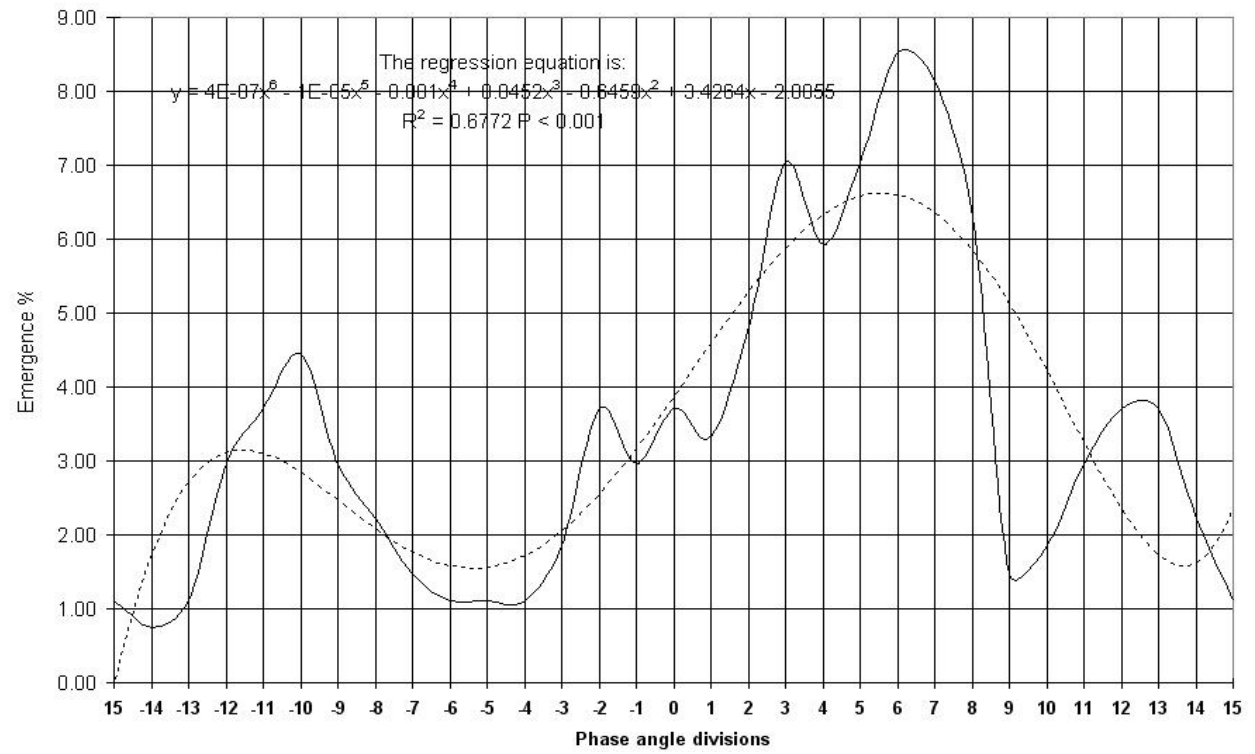

Figure 11. The emergence of the Coleoptera species caught by the Varga-Mészáros type lighttrap in Becse (Voivodina, Serbia) 


\section{Discussion}

The examination of the Macrolepidoptera material of the National Light Trap Network leads to results very similar as the ones based on data of the Kámon Botanical Garden (Fig. 1). The flight of 23 species was proved to start most often in the last quarter, or also in the last quarter. The flight of only five species began most often at a full moon. The highest frequency values of the adult brood emergences of the species examined from the material of the National Light Trap Network can all be well described by quadratic polynomials.

The flight of the Winter Moth (Operophtera brumata L.) is significantly more frequent in the waning than in the waxing phases of lunation. There is also a significant difference between the frequencies of the First and Last Quarter, the ones of a Full Moon and the Last Quarter and the ones of a Full Moon and a New Moon. The frequency of flights beginning between phase angle divisions -9 and 5 can be described by a quadratic polynomial. It is remarkable that the increase lasts only until phase angle division 5. An explanation for the latter might be that in the vicinity the Last Quarter, the Moon is above the horizon only after midnight, the approximate time until the species could experience the presence of the Moon.

The beginning of the flights of the Fall Webworm (Hyphantria cunea Drury) between 1953-1963 and 2000-2006 do not show a significant deviation in any of the lunar quarters. Between 1953 and 1963, flights starting at a Full Moon are significantly less frequent than in the other lunar quarters. In the 2000-2006 period, this significant deviation is only true when compared to the First Quarter, but even then, flights start most often in the First and Last Quarters, like in the years 1953-1963. The broods of the Common Cockchafer (Melolontha melolontha L.) start most often in the First or Last Quarter. On the other hand, broods begin significantly more often in the waxing, than in the waning lunar phases. Adult broods emerge vicinity a Full Moon less frequently than in any other quarter.

Our results prove that the emergence of the adult brood of at least some of the Macrolepidoptera and Coleoptera species is associated with a special lunar phase, most often with the Last Quarter (Fig. 3 and Fig. 11). The lifespan of Lepidoptera species is usually short, so there might be some kind of timing factor that ensures that mature individuals find each other. The regularly alternating lunar phases seem to be most suitable for this purpose. The decrease of light trap catch during a Full Moon reported by most scientists might, in our view, be at least partially explained by the relationship between the life cycle of insects and the moon phases.

Although we cannot preclude, that light traps cannot detect the emergence of adult broods in the same ratio during a Full Moon, as in the First and Last Quarters. This possibility raises the question of why adult broods emerge less frequently also around a New Moon, as moonlight might have no influence in these periods. Further investigation is certainly needed to answer this question.

On the other hand, it should also be noted, that the appearance of first specimen in the light trap does not necessarily mean the beginning of the flight of adults, though in the case of the common cockchafer (Melolontha melolontha L.) the trap catches specimen already on the very first day (Homonnay and Csehi, 1990). The first dispersing or migrating specimen caught by the light trap might cause further unreliability, as these might not have developed at the exact locality. This indicates a possible connection between migration and the lunar phases.

APPLIED ECOLOGY AND ENVIRONMENTAL RESEARCH 8(1): 51-62. http://www.ecology.uni-corvinus.hu • ISSN 15891623 (Print) • ISSN 17850037 (Online) (C) 2010, ALÖKI Kft., Budapest, Hungary 


\section{REFERENCES}

[1] Agee, H.R. (1972): Sensory response of the compound eye of adult Heliothis zea and $H$. virescens to ultraviolet stimuli. - Ann. Ent. Soc. Am. 65: 701-705.

[2] Bowden, J. (1973a): The influence of moonlight on catches of insects in light-traps in Africa. Part I. - Bull. ent. Res. 63: 115-128.

[3] Bowden, J., Gibbs, D.S. (1973): Light-trap and suction trap catches of insects in the northern Gezira, Sudan in the season of south ward movement of the inter tropical front. - Bull. ent. Res. 62: 571-596.

[4] Conlee, J. (1995): Influence of the Moon on Pheromone Trap Captures and Generation Emergences of Codling Moth in Southern California (Kern County). - Proceedings of the 69th Annual Western Orchard Pest \& Disease Management Conference: 88-90.

[5] Corbet, Ph.S. (1958): Lunar periodicity of aquatic insects in lake Victoria. - Nature 182: 330331.

[6] Csongor, Gy., Móczár, L. (1954): The Tisza mayfly (Palingenia longicauda) (in Hungarian). - Múzeumi Füzetek.

[7] Danthanarayana, W. (1986): Lunar periodicity of insect flight and migration. - In: Danthanarayana, W. (1986): Insect flight: Dispersal and migration. Springer Verlag. BerlinHeidelberg, 88-119.

[8] Fryer, G. (1959): Lunar rhythm of emergence, differential behaviour of the sexes and other phenomena in the African midge, Chironomus brevibucca (Kieff.). - Bull. ent. Res. 50: $1-8$.

[9] Hartland-Rowe, R. (1955): Lunar rhythm in the emergence of Ephemeroptera. - Nature 196: 657.

[10] Homonnay, F., Csehi, É. (1990): Cockchafers (in Hungarian). - In: Jermy, T., Balázs, K. (1990): Handbook of Plant Protecting Zoology 3/A: 169-184.

[11] Hora, S.L. (1927): Lunar periodicity in the reproduction of insects. - J. Asiatic. Soc. Bengal 23: 339-341.

[12] Ito, K., Sugiyama, H., Salleh, N.M.N.b.N., Min, Ch.P. (1993): Effect of lunar phase on light trap catches of the Malayan black rice bug, Scotinophara coarctata (Heteroptera: Pentatomidae). - Bull. ent. Res. 83: 59-66.

[13] McDonald, W.W. (1956): Observations on the ecology of Chaoborids and Chironomids in Lake Victoria and on the feeding habits of the elephant-snout fish (Mormyrus kannume Forsk.). - J. Anim. Ecol. 25: 36-53.

[14] Móczár, L. (1957): More closely with insects (in Hungarian). - Bp. Bibliotheca, 237.

[15] Nemec, S.J. (1971): Effects of lunar phases on light-trap collections and populations of bollworm moth. - J. Econ. Ent. 64: 860-864.

[16] Nowinszky, L. (2003): The Handbook of Light Trapping. - Savaria University Press, 276.

[17] Perfect, T.J., Cook, A.G. (1982): Diurnal periodicity of flight in some Delphacidae and Cicadellidae associated with rice. - Ecol. Entomol. 7: 317-326.

[18] Nowinszky, L., Ekk., I. (1988): The swarming outset of Macrolepidopterae observed by light-trap as correlated with the moon phases. - Acta Phytopathologica Hungarica 23(12): $157-166$.

[19] Nowinszky, L. (2004): Nocturnal illumination and night flying insects - Applied Ecology and Environmental Research, 2(1): 17-52.

[20] Nowinszky, L., Mészáros, Z., Puskás, J. (2007): The hourly distribution of moth species caught by a light trap - Applied Ecology and Environmental Research, 5(1):103-107.

[21] Nowinszky, L., Mészáros, Z., Puskás, J. (2008): The beginning and the end of the insects' flight towards the light according to different environmental lightings - Applied Ecology and Environmental Research, 6(2): 135-143.

[22] Persson (1974): Diel distribution of oviposition in Agrotis ipsilon (Hufn.), Agrotis munda (Walk.), and Heliothis armigera (Hbn.) (Lep., Noctuidae), in relation to temperature and moonlight. - Entomol. Scand. 5: 196-208.

APPLIED ECOLOGY AND ENVIRONMENTAL RESEARCH 8(1): 51-62. http://www.ecology.uni-corvinus.hu • ISSN 15891623 (Print) • ISSN 17850037 (Online) (c) 2010, ALÖKI Kft., Budapest, Hungary 
[23] Pongrácz, S. (1933): The mayfly (in Hungarian). - Publications of Natural Sciences 262270.

[24] Raulston, J.R., Lingren, P.D., Sparks, A.N., Martin, D.F. (1979): Mating interaction between native tobacco budworms and released backcross adults. - Environmental Entomology 8(2): 349-353.

[25] Roux, O., Baumgartner, J. (1995): Potato-tuber moth Phthorimaea operculella (Zeller) (Lep, Gelechiidae) and tuber infestation in Tunisian potato fields - Analysis of the flight phenology. Journal of Applied Entomology - Zeitschrift für Angewandte Entomologie, 119(5): 315-319.

[26] http://aa.usno.navy.mil/data.docs/MoonPhase.html 